\title{
Presumed metastatic transitional cell carcinoma of the choroids
}

\author{
H. R. ATTA \\ From the Department of Ophthalmology, Southern General Hospital, Glasgow G51 4TF
}

SUMMARY Ocular metastases from urinary tract carcinoma are extremely rare. Three previous cases of choroidal metastases from transitional cell carcinoma from the urinary bladder have been described, as have 2 cases of orbital metastases from bladder carcinoma. This is believed to be the first reported case of choroidal metastasis from transitional cell carcinoma of the renal pelvis in a 50-year-old female patient. The tumour, despite the absence of extension beyond the pelvic wall, showed disseminated metastases that proved resistant to chemotherapy. The fluorescein angiographic and ultrasonographic findings are described and the literature is briefly reviewed.

Horner in $1864^{1}$ reported the first orbital and Perl in $1872^{2}$ the first choroidal metastasis. Since then metastatic tumours to the eye and its adenexa have been regularly, albeit infrequently, reported from various bodily organs. Greear in $1950^{3}$ reviewed the literature and placed the total number of patients described at 300. A further review by Albert and associates in $1967^{4}$ recorded an additional 158 patients, and in 1974 Ferry and Font ${ }^{5}$ reported a further 227 cases.

Metastatic ocular tumours are regarded as the second most common intraocular tumours, being preceded by malignant melanoma. ${ }^{6-10}$ However, recent studies ${ }^{411-13}$ have established that the most common malignant tumour of the adult eye is in fact metastatic carcinoma. It is accepted that the breast is the most common site of primary tumour,,$^{5-8}$ being followed in order of frequency by malignancy of the lung, alimentary tract (mainly stomach), and less commonly thyroid, prostate, kidney, testicle, pancreas, ovary, and liver.

Urinary tract carcinoma is a very rare source of ocular metastases. In a survey by Hart in $1962^{10} 2$ cases of ocular metastases from bladder cancer were cited, but detailed descriptions were not given. Three cases of choroidal metastases ${ }^{14}$ and 2 of orbital metastases ${ }^{16}{ }^{17}$ from transitional cell carcinoma of the bladder have been fully described. However, there is no previous report of ocular metastasis from carcinoma of the renal pelvis. The present study

Correspondence to Mr H. R. Atta. describes a case of carcinoma of the renal pelvis that recurred in the urinary bladder and at a later stage showed generalised miliary metastases, including both choroids.

\section{Case report}

A 50-year-old housewife was admitted in September 1980 for investigation of painless haematuria. Ultrasound examination and arteriography of the left kidney revealed a mass in the renal pelvis, and fine needle biopsy disclosed the presence of malignant

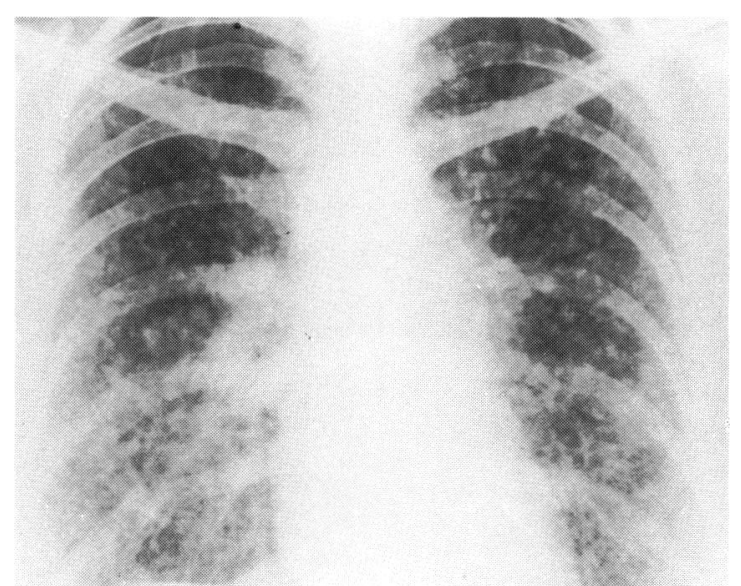

Fig. 1 Chest $x$-ray showing miliary metastases as small, multiple opacities throughout both lung fields. 830 


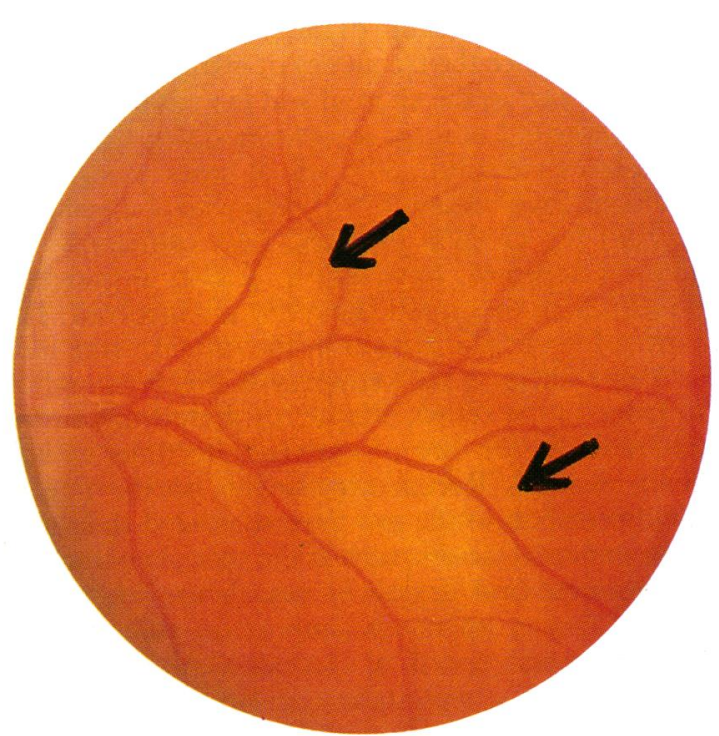

Fig. 2 Fundus picture showing two pale, slightly elevated lesions (arrows) below and lateral to the left macula.

cells. The patient underwent left nephrectomy, and histopathological examination reported 'moderately differentiated' transitional cell carcinoma arising from the renal pelvis. The tumour was confined to the pelvis, with no evidence of extension beyond the pelvic mucosa. The patient was discharged after uncomplicated recovery.

Thirteen months later she presented with recurrent haematuria and a mass was located at the bladder neck. Transvesical resection was performed, and histologically the tumour was found to be identical to the pelvic tumour previously removed. At this stage there was no evidence of extravesical extension. Thereafter the patient was readmitted on several occasions for repeated resection of recurring bladder tumour. A chest $x$-ray in December 1981 showed no abnormality.

In October 1982 she was readmitted as an emergency with severe haemoptysis. On examination an enlarged left cervical node was located. A chest $x$-ray revealed multiple opacities throughout both lung fields consistent with miliary metastases (Fig. 1). Microbiological examination of sputum excluded tuberculous infection; and excision biopsy of the left cervical node disclosed malignant cells consistent with metastasis from the renal pelvic carcinoma.

\section{OPHTHALMIC PRESENTATION}

Three days before her last admission to hospital the patient complained of 'bright spots' before her left eye. On examination of the left fundus 2 slightly elevated pale masses were observed. These were



Fig. 3 Fluorescein angiogram (left eye) 90 seconds after dye injection. Intense fluorescence from both masses developed due to leakage of dye from abnormal capillaries and staining of tumour tissue.

located below and lateral to the macular area (Fig. 2). The size of the nasally situated mass was a half disc while the second mass measured 2 discs in diameter. Both lesions were located subretinally, and the overlying retina and vitreous appeared normal; in particular there was no evidence of retinal detachment. Visual acuity at this stage was normal in both eyes, and funduscopy of the right eye showed no abnormality. Fluorescein angiography (Fig. 3) demonstrated very early leakage of dye from both masses.



Fig. 4 Ultrasonographic view of the left eye demonstrating an elevated mass in the choroid about $3 \mathrm{~mm}$ in diameter (arrow). The solid nature of the lesion is shown by the high density of echoes. 
The leakage occurred simultaneously with choroidal filling and before complete filling of retinal circulation. The focal fluorescence of both masses persisted up to the late frames when the retinal and choroidal fluorescence had faded. There was no leakage at the macula and the right fundus appeared normal. B-scan ultrasound examination of the left eye (Fig. 4) confirmed the presence of 2 raised, solid lesions arising from the choroid, the larger of which was approximately $3 \mathrm{~mm}$ in height.

\section{SUBSEQUENT EXAMINATION}

Systemic chemotherapy was started but the response was poor. In December 1982 bone scan and pelvic bone $x$-rays showed evidence of metastasis involving the sacrum and acetabulum, and local radiotherapy was given. In January 1983 examination of the right eye revealed 3 well circumscribed metastatic lesions in the posterior aspect of the choroid, the appearance of which resembled those found in the left eye on the initial presentation. In the left eye the two masses had grown considerably, with extensive detachment of the overlying retina. The lesions involved most of the lower lateral quadrant of the fundus and encroached on the macula, thus reducing visual acuity to finger counting. No extraocular extension was clinically noted, and both eyes remained painless. Radiation therapy was begun to the left eye, but the patient's condition deteriorated rapidly and she died in February 1983. Permission for post-mortem examination was not given.

\section{Discussion}

Metastatic tumours to the eye were first described about a hundred years ago. Since then more than 700 cases have been reported. Ocular metastases have been shown to supersede malignant melanoma as the commonest intraocular tumour in adults. Recent studies have demonstrated that the true frequency of ocular metastases can best be obtained by searching for the presence of ocular involvement in large series of patients or autopsies of patients known to have general malignancies. ${ }^{411} 12$ The reason for the relative infrequency of reported metastatic eye disease is the scarcity of enucleated eyes with metastases, since enucleation is required only in the event of intractable pain. Hart $^{10}$ estimated that in 1958 there were about 4000 melanoma specimens but only 133 metastatic carcinomas to the eyeball and its adenexa. Furthermore patients with terminal malignancies are seldom examined by ophthalmologists, since metastatic foci to the eye are often overlooked in the seriously ill patient, especially if they are asymptomatic.

The mode of spread of tumours to the eye is haematogenous. Tumour emboli usually enter the eye through one or more of the short posterior ciliary arteries. ${ }^{8}$ Hence the frequency of involvement of the posterior part of the choroid and the not uncommon appearance of 2 or more separate nodules. Choroidal metastases constitute $50 \%$ of all cases of eye and adenexal involvement, ${ }^{51011}$ while orbital metastases account for $12-14 \%$ of cases. Less commonly the anterior segment, optic nerve, sclera, extraocular muscles, and very rarely the retina are involved. The rarity of neoplastic growth in the retinal tissue is in striking contrast to the frequency of infectious emboli to lodge in the retina. Reese ${ }^{7}$ attributed this to the difference in the size of emboli (infectious emboli being smaller). Recent experiments on the fate of tumour emboli to the eye have suggested that local environmental factors, such as the special anatomical arrangement and degree of vasculature of various ocular tissues, play an important role in the frequency and speed of development of tumour emboli into metastatic growth. ${ }^{18}$ Bilateral involvement is present in about $20 \%$ of cases, ${ }^{81013}$ but the left-side predominance previously reported ${ }^{10}$ has not been confirmed in recent surveys. ${ }^{4511}$ Reviews of large numbers of cases ${ }^{410}$ have shown that after carcinoma of the breast and lung the third largest category of patients with ocular metastases are those with no known primary malignancy. In Ferry and associates' series of 227 cases $^{5}$ there were 41 patients with ocular metastases in whom the site of the primary tumour was undetermined. It has also been shown that in a considerable number of patients (up to $46 \%$ in Ferry's series) ocular signs and symptoms preceded the diagnosis of the primary tumour. Although pulmonary metastasis appears to be a prerequisite for the subsequent development of ocular secondaries, since ocular emboli develop in the arterial circulation, Ferry ${ }^{19}$ found no metastatic lung lesions in $15 \%$ of autopsies of patients with ocular metastases.

Carcinoma of the renal pelvis is relatively rare in comparison with carcinoma of the urinary bladder. During the 20 years up to 1970 the Bristol Bladder Tumour Registry reported 43 cases of carcinoma of the renal pelvis and 2770 cases of bladder carcinoma. The incidence of both pelvic and bladder carcinoma is 3 times greater in males. ${ }^{20}$ Various studies have suggested that there has been a considerable increase in the incidence of cancer of the renal pelvis in recent years. ${ }^{2021}$ Transitional cell carcinoma constitutes about $90 \%$ of all tumours of the renal pelvis. Squamous cell and adenocarcinomas comprise most of the remaining $5-10 \% .{ }^{22}$

The subsequent development of bladder carcinoma in the present study is not surprising, since a considerable group of patients with renal pelvic carcinoma will develop cancer elsewhere in the urinary 
tract. ${ }^{2022}$ This reflects the recently accepted theory of independent multifocal origin of urinary tract carcinoma, and supports the hypothesis that a carcinogenic substance(s) is present in the urine of these patients. ${ }^{22} 23$

In the present case it is difficult to be certain whether the ocular and systemic metastases have developed from the renal pelvic or bladder carcinoma, since both showed identical histological appearance. Of greater interest, however, is the abrupt onset of disseminated metastases, which took the form of miliary spread; hence the appearance of chest $x$-ray and the development of multiple nodules in both choroids. The pattern of metastasis and the absence of tumour extension beyond the pelvic and bladder walls may indicate that tumour cell emboli had escaped into the lymphatic and/or systemic circulation at an early stage of the disease. Also of interest are the morphological appearance of the choroidal metastases, the appearance on fluorescein angiography and ultrasonography, and the rapid growth of the left choroidal tumours, which reflected the lack of response to systemic chemotherapy.

Recognition of the high incidence of metastatic intraocular tumours is important for several reasons. A high index of suspicion will reduce the number of cases of incorrect diagnosis of malignant melanoma and its sequelae. Ocular secondaries are the first manifestation of systemic malignancy in a considerable number of cases, even without clinical or radiological evidence of pulmonary metastasis. Fluorescein angiography is of value in the diagnosis of ocular metastases. Furthermore early diagnosis and prompt treatment may result in reduction in visual morbidity and improved prognosis. Intraocular metastases can be a suitable site for observing the nature and behaviour of various malignancies. Further studies on the mechanisms of development of ocular metastases are merited.

I thank Mr E. S. Glen, consultant urologist, Southern General Hospital, Glasgow, for his permission to submit this case report, and Dr G. McCreath, consultant radiologist, Southern General Hospital, Glasgow, for her valuable assistance in supplying and reporting on the radiological films.
I also thank Dr J. V. Forrester, consultant ophthalmologist, Southern General Hospital, Glasgow, for his invaluable co-operation and advice in writing the paper.

\section{References}

1 Horner F. Carcinoma der Dura Mater. Exphthalmos. Carcinom der muscl Recti. Allgemeine Carcinose. Klin Monatsbl Augenheilkd 1864; 2: 186-90.

2 Perl M. Contributions to pathology of tumours. Virchow's Arch Pathol Anat 1872; 56: 445-8.

3 Greear JN. Metastatic carcinoma of the eye. Am J Ophthalmol 1950; 33: 1015-25.

4 Albert DM, Rubenstein RA, Scheie HG. Tumour metastasis to the eye, part I. Am J Ophthalmol 1967; 63: 723-6.

5 Ferry AP, Font RL. Carcinoma metastatic to the eye and orbit: a clinicopathologic study of 227 cases. Arch Ophthalmol 1974; 92: 276-86.

6 Yanoff M, Fine BS. Ocular pathology. 2nd ed. New York, Harper and Row, 1982: 428.

7 Reese AB. Tumours of the eye. New York: Hoeber, 1951: 496.

8 Duke-Elder S, Perkins ES. Diseases of the uveal tract. In: DukeElder S, ed. System of ophthalmology. St Louis: Mosby, 1966: 917.

9 Hogan MJ, Zimmerman LE. Ophthalmic pathology. 2nd ed. Philadelphia: Saunders, 1962: 413.

10 Hart WM. Metastatic carcinoma to the eye and orbit. Int Ophthalmol Clin 1962; 2: 465-82.

11 Bloch RS, Gartner S. The incidence of ocular metastatic carcinoma. Arch Ophthalmol 1971; 85: 673-5.

12 Güthert H, Jänisch W, Rossbach K. Ueber die häufigkeit der Augenmetastasen. Munch Med Wochenschr 1965; 107: 939-41.

13 Brady LW, Shields JA, Augsburger JJ, Day JL. Malignant intraocular tumours. Cancer 1982; 49: 578-85.

14 Gordon HL, Munro R. Ocular metastasis of bladder cancer. South Med J 1974; 67: 745-6.

15 Resnick MI, O'Connor VJ, Grayhack JR and JT. Metastases to the eye from transitional cell carcinoma of the bladder. J Urol 1975; 114: 722-4.

16 Smiley SS. An orbital metastasis from the urinary bladder. Arch Ophthalmol 1965; 74: 809-10.

17 Krauss HR, Slamovits TL, Sibony PA, Dekker A, Kennerdell JS. Orbital metastasis of bladder carcinoma. Am J Ophthalmol 1982; 94: $265-6$.

18 Albert DM, Zimmermann AW, Zeidman I. Tumour metastasis to the eye: part III. Am J Ophthalmol 1967; 63: 733-8.

19 Ferry AP. Metastatic carcinoma of the eye and ocular adenexa. Int Ophthalmol Clin 1967; 7: 615-58.

20 Williams CB, Mitchell JP. Carcinoma of the renal pelvis: a review of 43 cases. Br J Urol 1973; 45: 370-6.

21 O'Connor VJ. The diagnosis of tumours of the renal pelvis and ureter. J Urol 1956; 75: 416-8.

22 Skinner DG, de Kernion JB. Genitourinary cancer. Philadelphia: Saunders, 1978: 137-47.

23 Wallace DM. Urothelial neoplasia: causes, assessment and treatment. Ann R Coll Surg Engl 1972; 51: 91-102. 